\title{
CONTINUING PROFESSIONAL COMPETENCE: VOLUNTARY OR LEGISLATED? A PANEL DISCUSSION
}

\author{
S.L. VANDEWATER* \\ Chairman
}

\section{INTRODUCTION}

"There is a growing awareness amongst the public as well as in the profession, that, in this age of rapid technological and scientific advance, initial education can no longer fit a man or woman to practise medicine (Anaesthesia) for the whole of his or her professional career. The pace of change in society at large constitutes the major source of awareness for the need for continuing education and the documentation that this need is recognized and is being met."

The objective of this panel discussion was to explore the nature, development and need for continuing education of physicians, and whether or not the documentation of participation in educational exercises can be related to professional competence. Developments in other jurisdictions, particularly in the United States, suggest that competence can be legislated through mandatory and documented continuing medical education.

\section{"ISSUES in the United STATes of America"}

Dr. Nicholas M. Greene, Professor of Anesthesiology, Yale University, New Haven, Conn.; Editor-in-Chief of "Anesthesia and Analgesia"

Dr. Greene stated that continuing medical education has become one of the largest "growth industries" in medicine in the U.S.A. today. The number of currently "approved" courses, seminars and symposia for physicians is awesome,

Editorial Note: This Synopsis of a Panel Discussion held at the Annual Meeting of The Canadian Anaesthetists' Society in June, 1978, has been prepared by Dr. S.L. Vandewater, Chairman of the Panel.

${ }^{*}$ S.L. Vandewater, M.D., F.R.C.P.(C), Professor, Department of Anaesthesia, and Associate Dean, Faculty of Medicine, Queen`s University, Kingston. Ontario. having grown in ten years from zero to over 7,000 in 1977. This growth is mainly the result of the introduction in 1970 of the Physician"s Recognition Award (P.R.A.) by the American Medical Association which was intended as a stimulus for physicians to pursue voluntarily various categories of educational activities, including attendance at formal courses of instruction (accredited courses). This formalization of continuing medical education activities was undertaken in recognition of the explosion of new medical knowledge and the fact that physicians cannot retain their professional competence unless they are aware of these changes.

In parallel with the professional basis for continuing medical education, societal pressures developed through increasing public disenchantment with the level of competence of some physicians. Thus the Physician's Recognition Award became an instrument, perhaps inadvertently, to reassure the public that doctors can and do maintain their competence. However, it is now evident how voluntary professional activities. combined with a disenchanted society, resulted in political pressures and the generation of legislation for mandatory continuing medical education.

The noble objectives of continuing medical education requirements manifested by the Physician's Recognition Award have been seized upon by a variety of organizations and individuals as a means of quantifying or proving continued medical competence. The use of the Physician's Recognition Award as prima facie evidence of medical competence has happened in five major areas and one should not underestimate the significance of any one of these five, let alone the combined effect.

The five areas in which continuing medical education, Physician's Recognition Award and medical competence have been equated are:

(1) relicensure or reregistration requirements in a growing number of States

(2) malpractice insurance

(3) hospital privileges, 
(4) membership in State Medical Societies and national professional associations,

(5) recertification by specialty boards, including the American Board of Anesthesiology, which will require the Physician's Recognition Award as a precondition to taking the recertification examination in 1984.

The Physician's Recognition Award approach to the goals of continuing medical education is rapidly being institutionalized as the only acceptable way to judge medical competence. This is happening in the absence of even a shred of evidence to prove the validity of the Physician's Recognition Award as an index of professional competence.

Totally untested criteria have been and are being seized upon, not only as a basis for establishing membership in professional organizations, but even as the legal basis for determining who can and who can not practise medicine. Who can practise medicine and how they practise it is increasingly being determined legally, by legislation passed by legislators who have no actuarial basis for the laws they pass. This is Dr. Greene's major concern. He believes that continuing medical education is necessary but questions whether it can or should be used by those outside medicine to determine who can practise medicine. He also seriously questions the blind faith of certifying Boards and other professional organizations in the Physician's Recognition Award as evidence of competence.

\section{"The View of a Licensing Authority",}

Dr. Andre Sindon, Anaesthetist and Member of the Division of Continuing Medical Education,

Professional Corporation of Physicians of Quebec

Licensing bodies are primarily concerned with quality of care, the end product of maintenance of competence. Quality care is mandatory for all physicians. Three Canadian provinces already have legislation in place that gives the licensing body the authority to monitor the quality of health care. It is foreseeable that in the near future all licensing authorities will have to establish evaluation mechanisms to judge quality and hence the competence of physicians. The criteria for such a mechanism will have to take into account the type of practice and limitation if any; the individual physician's self-learning habits; the impact on quality of care and, ultimately, provide public accountability.

At the moment there are three possible ways for licensing bodies to evaluate professional practice. These are examination (preferably in problem solving), peer review and recognition of point system from accredited programs; Doctor Sindon agreed with Doctor Greene that there is no proof that the latter can be equated with competence.

He went on to relate the experience in peer review of the Professional Corporation of Physicians of Quebec, believing that this means of assessing competence related to quality care is next to best in respecting the ideal criteria for an evaluation mechanism. The Corporation of Physicians of Quebec established a special division to evaluate patient care in 1970 . This was a voluntary development and not related to public pressures. To date, patient care has been periodically evaluated in more than 141 hospitals and 700 evaluations have been carried out in the offices of some 555 doctors. These peer reviews have identified the incompetent and marginally competent physician and some common practice errors such as over-use of drug medication.

As an example, Doctor Sindon briefly reviewed the procedure for evaluation of a 300 -bed community hospital by a team of peers representing the Corporation. If an individual or group of doctors are found to have educational needs, he or they can be referred to the Continuing Medical Education Division of the Corporation, which finds an appropriate solution for remedial (continuing) education. Periodic reports of these peer reviews are forwarded to the Board of Directors of the Corporation which includes representatives of the public. This system is costly and time-consuming.

In conclusion. Doctor Sindon stated that the ideal feasible means of evaluating quality care and being public accountable and doctor accountable is yet to come.

\section{"Public Expectations"}

Ms. Joan Hollobon, Medical Reporter for The Globe and Mail, Toronto

Ms. Hollobon statec at public expectations could be summed up in two simple phrases: 
Expect to be protected,

Expect to be communicated with.

These expectations applied to all doctors and other health professionals, but were particularly appropriate to anaesthetists. Entrusting oneself to an anaesthetist to be rendered unconscious is particularly frightening, at least as frightening and, to many people, more frightening than the actual surgical operation. Things become familiar by repetition; giving anaesthetics is familiar to anaesthetists; anaesthesia is not familiar to patients.

Ms. Hollobon emphasized the enormous amount of trust implied by patients in submitting to anaesthesia. Losing consciousness carries age-old atavistic fears of vulnerability, a loss of control over one's situation, even one's life.

Protection implies to the patient not only scrupulous attention to duties, but also that the anaesthetist is conscientious in keeping his knowledge up to date. The public is told that the profession's conscience is the best safeguard, that mandatory re-education and enforced external scrutiny are not only unnecessary but actually counter-productive. Ms. Hollobon strongly rejected this line of argument. There is growing evidence to suggest that the public trust cannot be maintained by the profession's conscience. Examinations may not be the answer; peer review of clinical work may be better. If the profession does not accept the first, then the licensing authorities should move quickly to the second, as is happening in Quebec.

Ms. Hollobon went on to say that every study on public expectations of doctors carried out to date, best exemplified by the Pickering Report ${ }^{2}$ in Ontario, clearly show that lack of communication is the public's first complaint. In closing. Ms. Hollobon quoted from the Annual Report of the Health Disciplines Board, ${ }^{3}$ Ontario, 1976 :

"The most serious problem apparent to the Board is poor communication between practitioner and patient. In too many cases, the practitioner failed to tell the patient the whole story, sometimes in what the practitioner considered to be the patient's best interest; or there was a failure to relate personally.

"In some instances, the practitioner was seen by the patient as aloof, indifferent, callous or arrogant. There appear to be practitioners who either do not know how to listen or talk to their patients or who do not deem it worthwhile. They do not seem interested in their patients as people."
"Position of the Royal College of PhysiCIANS AND SURGEONS OF CANADA"

DR. JAMES A. DARRAGH, Internist. Lately

Associate Dean, Postgraduate Medical

Education, McGill University; now Director of Fellowship Affairs, Royal College of Physicians and Surgeons of Canada, Ottawa

Dr. Darragh spoke to four areas pertinent to the subject:

(1) competency defined,

(2) Royal College system for initial competence,

(3) Royal College policy on continuing competence.

(4) possible future developments.

Competence: Dr. Darragh outlined the difficulty in defining competence, and the ensuing problems of measuring it. In quoting several modern attempts at defining professional competence, the wording implies judgment coupled with recallable knowledge, clinical skills, and attitudes, as well as clinical facilities and the patient's point of view. It has been said that "the final evaluator will be the consumer". ${ }^{4}$

Initial Competence: The Royal College specialty certificate is recognized as proof of special competence in a branch of medicine or surgery in nine of the ten provinces, and may allow direct admission to the oral and clinical examination given by the Professional Corporation of Physicians of Quebec. This competence is determined by medical qualifications, completion of an approved specialty training programme of not less than four years' duration, satisfactory in-training evaluation, satisfactory moral and ethical standing and satisfactory performance in the written and oral examinations. There is no time-limit on a Royal College Certificate, although it does not predict future performance. The Royal College agrees with the American Board of Medical Specialties in its 1974 statement that "a certificate once given, cannot be withdrawn". similar to a university degree. However, there was a revision of the College By-laws in 1977, and a specialty certificate can be withdrawn for incompetence. Two of the American Specialty Boards (Surgery and Family Practice) now issue time-limited (self-destructing) certificates. To do so in Canada the potential trainees would have to be notified in advance, before starting residency training.

Dr. Darragh reviewed the changes which have taken place in the examination system and intro- 
duction of the multiple choice question examination in 12 of the 35 specialties, the increasing emphasis on in-training evaluation, and the requirements of on-site accreditation visits for programme approval.

Continuing Competence: It was pointed out that admission to Fellowship in the College. through phrases in the by-laws and the code of ethics, carries with it an agreed dedication to life-long planning of continuing education and professional development and a restriction of practice to the Fellow's stated area of competence. However, a certificant is not required to maintain competence in the complete range of a particular specialty, as many limit their practice to only a segment of that specialty, e.g. an anaesthetist becoming an intensivist, or a researcher, etc. In summary, there is a rigorous, controlled, initial qualification for primary competence and a Royal College requirement (voluntary) to maintain competence through life-long study, to do well, whatever it is that they do, and to maintain judgment to know what not to do.

The pressures to maintain competence come from several directions - from within oneself (self-esteem and the so-called work ethic in a highly selected group in the population), from professional colleagues, from patients, hospital staff appointments and their requirements, academic appointment (part-time and full-time), licensing authorities, medical associations and specialty societies such as The Canadian Anaesthetists' Society. Reference was made to the growing number of medical associations. societies and licensing authorities in the United States requiring documented evidence of continuing medical education and professional development to maintain status. and the warning that they may spread to Canada.

The recently established Committee on Fellowship Affairs of the Royal College of Physicians and Surgeons of Canada has studied the various attempts to legislate continuing professional competence. In January 1976 the Council of the College made a policy statement in favour of medical audit and peer review and opposed compulsory recertification and the documentation of credits in continuing medical education. The College is in favour of self assessment programmes and is prepared to co-operate with specialty societies in their development.

Possible Future Developments: Every certificant of the College should be able to defend his record to public challenge in respect to practice profile, maintenance of competence activities, and continuing medical education. Some Canadians have and will be taking recertification examinations offered by American specialty boards. Many physicians desire some form of public recognition that they have kept up to date. Recognizing this, the Committee on Fellowship Affairs approved the following in May, 1978: "that the Committee on Fellowship Affairs is in favour of recognizing continuing efforts to maintain competence and proficiency of the Fellows of the College". This motion is being studied by the Committee on Maintenance of Competence as to its implementation. The question now is, how will continuing competence be measured and how will it be recognized?

The American Board of Medical Specialties enunciated the following principles for recertification examinations in February, 1978: the examination should test more than knowledge; testing should be multi-factorial, and should test problem solving; performance should be examined; examination should be related to the area of practice of the candidate.

The main motivation for recertification is to provide the challenge that will motivate physicians to maintain their basic knowledge and skills and to keep up to date. It also provides visibility and a reward. However, most authorities agree that a valid, reliable and reproducible method for evaluating continuing clinical competence has yet to be devised.

\section{"Recertification; Why Me?"}

\section{Dr. Andrew O. Davies. Anaesthetist, North Bay, Ontario}

Dr. Davies framed his remarks as a physician who has just completed four years of postgraduate training, obtained his specialist certificate in Anaesthesia, and commenced practice in a moderate sized, non-university community hospital. He pointed out that medicine was not alone in the professions requiring documented evidence of continuing education (in U.S.A.). There is a growing number of State licensing authorities requiring continuing education for optometrists, accountants, veterinarians, pharmacists, nurses, dentists, and lawyers. The bare logic involved in recertification suggests that if some certified anaesthetists are incompetent, and if they will be upgraded or weeded out by continuing medical education, then all anaesthetists should be recertified by one or all of these devices. However, 
the first two statements contain assumptions that have never been proven true.

The definition of competence includes many complex elements such as knowledge, comprehension and psychomotor skills, which may be assessed, but other factors such as attitudes and motivation are impossible to quantify. The only two examples of controlled studies of the effect of continuing medical education on competence were cited, both restricted to very specific objectives and very expensive to achieve. The standard or usual continuing medical education programmes are of the didactic or lecture type, which do not alter patterns of practice or correct faulty concepts and bad habits. Continuing medical education can maintain excellence in the interested competent anaesthetist if well designed, but will not change the habits of the few who are less than competent.

Similarly, success in examinations, including those that purport to measure problem solving skills and attitudes, are difficult to correlate with competence. What is the body of knowledge required by an anaesthetist practising in a small community? Who can assure us (anaesthetists) as consumers of continuing medical education programmes, or as examinees, that our teachers and examiners are competent?

Dr. Davies believes that, pragmatically, the only effective way of monitoring competence is through peer review by the hospital department head. He believes present hospital by-laws make such peer review possible and practical. Another practical problem is the large number of practitioner anaesthetists with varying degrees of formal training. Dr. Davies believes that the public good would be better served and the public purse better spent by upgrading the qualifications of uncertified anaesthetists.

Dr. Davies closed by recounting his own voluntary plan for maintaining competence, through an arrangement to exchange practices with a member of the staff of a teaching hospital for a few weeks each year. Adults may be coerced into attending continuing medical education programmes or studying for examinations, but learning related to patient care and subsequent application of knowledge can not be forced. This is where the challenge exists; to ensure that every anaesthetist has a thirst for knowledge, not to compare ways of forcing it down his throat.

\section{REFERENCES}

1. Vandewater, S.L. Take Post! A Vos Postes! Editorial, Canad. Anaes. Soc. Jour. 25: 161 (1978).

2. Pickering, E.A. Report of the Special Study Regarding the Medical Profession In Ontario. Ontario Med. Association (1973).

3. The Health Discipline Board 1976. Annual Report to the Minister of Health, Ontario. Ontario Government Publications.

4. StaAd, E.A. Measuring Competence. Ann. Int. Med. 86: 501 (1977). 